\title{
Plasma levels of total cholesterol, high-density lipoprotein-cholesterol, low-density lipoprotein-cholesterol, triglyceride, Apo A-1, and Apo B in patients with Stroke in Ogbomoso, Southwestern Nigeria
}

\author{
J. O. Akande ${ }^{1}$, A. A. Salawu², A. S. Atiba ${ }^{3}$, E. O. Oke', R. O. Akande, D. P. Oparinde ${ }^{2}$, P. S. Ogunro ${ }^{2}$
}

${ }^{1}$ Department Chemical Pathology, Bowen University, Iwo, Nigeria, ${ }^{2}$ Department Chemical Pathology, Lautech, Ogbomoso, Nigeria, ${ }^{3}$ Department Chemical Pathology, Ekiti State University, Ado-Ekiti, Nigeria, ${ }^{4}$ Department Community Medicine Lautech Teaching Hospital, Ogbomoso, Nigeria

\section{ARTICLE INFO}

Article history:

Received on: July 18, 2018

Accepted on: November 25, 2018

Available online: April 05, 2019

\section{Key words:}

Stroke,

Apo A1,

Apo,

Lipid profile,

Dyslipidemia

\section{ABSTRACT}

Hyperlipidemia is a strong factor in the development of stroke, but this may differ from one region to another due to geographic, ethnic, and sociocultural practices. This is designed to determine plasma levels of total cholesterol, high-density lipoprotein (HDL)-cholesterol, low-density lipoprotein (LDL)-cholesterol, triglyceride, Apoprotein A-1, and Apoprotein B in Nigerian patients with stroke. 50 newly diagnosed stroke patients were consecutively recruited into the study. 50 apparently healthy, age- and sex-matched volunteers were recruited from Ogbomoso community as controls. The data obtained were analyzed using the Statistical Package for the Social Sciences (SPSS) version 20. Higher and lower significant levels $(P<0.001)$, respectively, were observed in the plasma total cholesterol $(4.5 \pm 1.41$ vs. $3.90 \pm 0.91 \mathrm{mmol} / \mathrm{l})$, LDL-cholesterol $(3.32 \pm 1.41 \mathrm{vs.} 2.19 \pm 0.82 \mathrm{mmol} / \mathrm{l})$, HDL-cholesterol $(0.76 \pm 0.32$ vs. $1.27 \pm 0.38 \mathrm{mmol} / \mathrm{l})$, and Apo A1 $(0.87 \pm 0.73$ vs. $4.56 \pm 2.40)$ in stroke patients when compared with controls. There was a lower significant difference in plasma level of Apo A1 in patients with ischemic stroke $(0.734 \pm 0.64$ vs. $1.31 \pm 0.84)$ when compared with hemorrhagic stroke $(P<0.005)$. The mean plasma level of Apo B $(1.70 \pm 1.05$ vs. $1.09 \pm 0.40)$ in ischemic stroke was higher than patients with hemorrhagic stroke, though difference was not statistically significant $(P \geq 0.005)$. We concluded that apoproteins remain the significant biochemical markers that may be deranged in patients with stroke. There are associations between Apo A1 and Apo B. It is encouraged that plasma apoproteins estimation should be added to routine investigations done on stroke patients in this environment.

\section{INTRODUCTION}

Global estimates of disease burden indicate that over the next two decades, cerebrovascular disease will continue to rank among the top four leading causes of death, even in developing countries [1]. The World Health Organization estimates that by the year 2030, $80 \%$ of all strokes will occur in low- and middle-income countries [2]. Plasma lipid profile and apolipoproteins determination play a key role in the management of the cases of stroke [3,4]. Dyslipidemia has been associated with the pathogenesis of stroke $[2,3]$.

Elevated total cholesterol, low-density lipoprotein (LDL)-cholesterol, triglyceride, apolipoprotein B, lipoprotein (a), and reduced highdensity lipoprotein (HDL)-cholesterol and apolipoprotein A are risk factors. Available global data have clearly established relationship between parameters of plasma lipid profile and stroke [4]. The use of

*Corresponding Author:

Dr. Joel O. Akande,

Department of Chemical Pathology,

College of Health Sciences, Bowen University, Iwo, Osun State, Nigeria.

E-mail: prophyjoe30@yahoo.com statin therapy aiming at lowering LDL-cholesterol has significantly reduced cardiovascular events and mortality, but substantial residual cardiac events still occur [4]. This may be as a result of its lack of therapeutic effect on all parameters of plasma lipids.

Apo A-I plays an important role in regulating HDL-cholesterol composition and functions such as anti-inflammation, antioxidation, antithrombosis, and vessel relaxation $[5,6]$.

Several studies from different parts of the world have established relationship between an increased risk of cerebrovascular accident (CVA) and decreased plasma levels of Apo A as well as increased Apo $\mathrm{B}[7,8]$. It has been observed that dyslipidemia in Africa does not follow similar pattern obtained in the rest of the world [9]. Hyperlipidemia is a strong factor in the development of CVA, but dyslipidemia differs from one region to another due to dietary, geographic, ethnic, and sociocultural practices [10]. Therefore, the pattern of lipid profile and other associated factors in Nigerian subject with stroke may be different. This study was, therefore, designed to determine the pattern of dyslipidemia and its association with apoprotein A-I and apoprotein B levels in patients with CVA in Ogbomoso Southwestern Nigeria. 


\section{MATERIALS AND METHODS}

The study population was newly diagnosed CVA patients presented at Ladoke Akintola University of Technology (LAUTECH) Teaching Hospital, Ogbomoso, and Bowen University Teaching Hospital, Ogbomoso, both in Oyo State, Nigeria. All recruited subjects are adults clinically diagnosed of CVA and confirmed with computed tomography scan. Subjects with additional complication such as renal or liver pathology were excluded from the study. Patients with suspected or established acute or chronic medical illnesses as well as those on lipid-regulating drugs were also excluded from the study. Carefully, history and physical examination were conducted from the subjects after which samples were taken for fasting plasma glucose (FPG).

The study was cross-sectional. 50 newly diagnosed CVA patients presenting at accident and emergency units of both institutions were consecutively recruited into the study after obtaining their informed consent. Another 50 apparently healthy normotensive, age- and sexmatched volunteers were recruited from Ogbomoso Community as controls after obtaining their informed consent.
A semi-structured questionnaire was used as the survey instrument to seek information of subjects' and controls' sociodemographic characteristics, risk factors for stroke, duration, and number of stroke attack and drug history.

Ethical clearances for the study were obtained from the Ethical Review Committee of LAUTECH Teaching Hospital and Bowen Teaching Hospital, both in Ogbomoso.

\subsection{Blood Sample Collection, Storage, and Laboratory Analysis}

After an overnight fast, $10 \mathrm{~mL}$ of venous blood was collected into $0.1 \%$ $\mathrm{Na}$ EDTA bottle from each subject and control using standard technique of phlebotomy. Each sample was centrifuged at $\times 3000 \mathrm{~g}$ for $5 \mathrm{~min}$. The plasma obtained was aliquoted into screw cap plain bottle and stored frozen at $-20^{\circ} \mathrm{C}$ for maximum period of 3 months before analysis. Plasma from both subjects and controls was analyzed in batches using standards and controls for all the biochemical parameters. Enzymatic end point was used for lipid profile parameters except LDL-cholesterol using kits from Randox Laboratories Limited, (Batch Number; CH 200 Lot 363904/97QX, TR 21032579987 D8, CH203 2344CH) Crumlin,

Table 1: Sociodemographic profile of the respondents

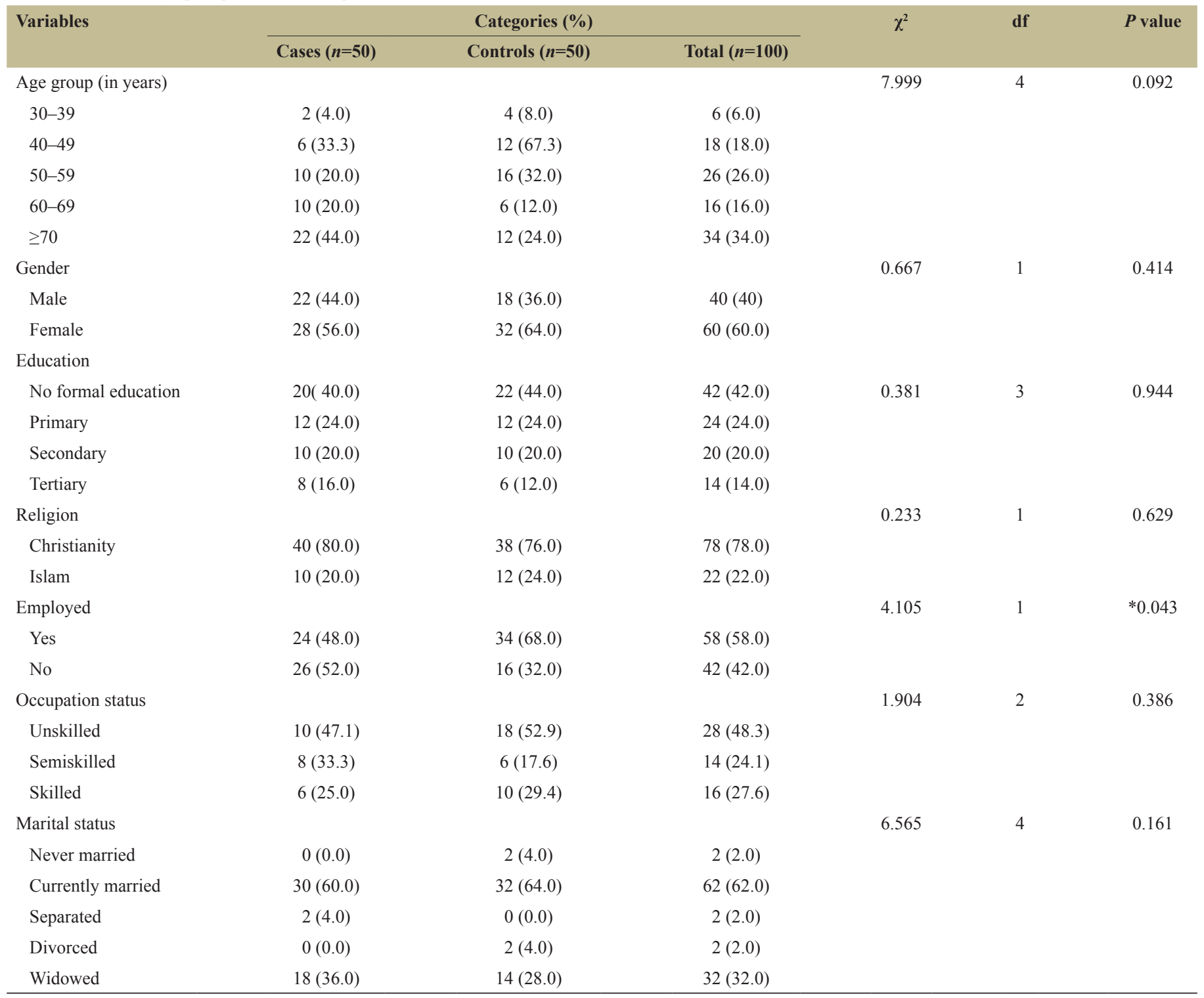


Table 2: Risk factors of the respondents

\begin{tabular}{|c|c|c|c|c|c|c|}
\hline \multirow[t]{2}{*}{ Variables } & \multicolumn{3}{|c|}{ Categories (\%) } & \multirow[t]{2}{*}{$\chi^{2}$} & \multirow[t]{2}{*}{ df } & \multirow[t]{2}{*}{$P$ value } \\
\hline & Cases $(n=50)$ & Control $(n=50)$ & Total $(n=100)$ & & & \\
\hline \multicolumn{7}{|l|}{ Alcohol intake } \\
\hline Yes occasionally & $4(8.0)$ & $2(4.0)$ & $6(6.0)$ & & & \\
\hline No but in the past & $4(8.0)$ & $4(8.0)$ & $8(8.0)$ & & & \\
\hline No never before & $36(72.0)$ & $42(84.0)$ & $78(78.0)$ & & & \\
\hline $1-10$ years & $2(20.0)$ & $4(100.0)$ & $6(42.9)$ & 7.47 & 1 & $* 0.015$ \\
\hline$>10$ years & $8(80.0)$ & $0(0.0)$ & $8(57.1)$ & & & \\
\hline \multicolumn{7}{|l|}{ Tobacco } \\
\hline Yes frequently & $0(0.0)$ & $2(4.0)$ & $2(2.0)$ & 4.17 & 2 & 0.125 \\
\hline No & $12(24.0)$ & $50(100.0)$ & $62(62.0)$ & & & \\
\hline \multicolumn{7}{|l|}{$\mathrm{DM}$} \\
\hline Yes & $6(12.0)$ & $0(0.0)$ & $6(6.0)$ & 6.38 & 1 & $* 0.012$ \\
\hline No & $44(88.0)$ & $50(100.0)$ & $94(94.0)$ & & & \\
\hline \multicolumn{7}{|l|}{ Other diseases } \\
\hline Yes & $2(4.0)$ & $0(0.0)$ & $2(2.0)$ & 2.04 & 1 & 0.153 \\
\hline No & $48(96.0)$ & $50(100.0)$ & $98(98.0)$ & & & \\
\hline \multicolumn{7}{|l|}{ BP drug } \\
\hline Yes & $38(76.0)$ & $0(0.0)$ & $38(38.0)$ & 61.29 & 1 & $*<0.001$ \\
\hline No & $48(96.0)$ & $50(100.0)$ & $98(98.0)$ & & & \\
\hline \multicolumn{7}{|l|}{ Exercise } \\
\hline Yes & $4(8.0)$ & $24(48.0)$ & $28(28.0)$ & 19.84 & 1 & $*<0.001$ \\
\hline No & $46(92.0)$ & $26(52.0)$ & $72(72.0)$ & & & \\
\hline \multicolumn{7}{|l|}{ Family history HNT } \\
\hline Yes & $20(40.0)$ & $8(16.0)$ & $28(28.0)$ & 10.74 & 2 & $*<0.001$ \\
\hline No & $22(44.0)$ & $38(76.0)$ & $60(60.0)$ & & & \\
\hline Do not know & $8(16.0)$ & $4(8.0)$ & $12(12.0)$ & & & \\
\hline \multicolumn{7}{|l|}{ Family history DM } \\
\hline Yes & $10(20.0)$ & $2(4.0)$ & $12(12.0)$ & 7.10 & 2 & $* 0.029$ \\
\hline No & $26(52.0)$ & $36(72.0)$ & $62(62.0)$ & & & \\
\hline \multicolumn{7}{|c|}{ Family history of stroke } \\
\hline Yes & $4(8.0)$ & $4(8.0)$ & $8(8.0)$ & 1.02 & 2 & 0.600 \\
\hline No & $38(76.0)$ & $34(68.0)$ & $72(72.0)$ & & & \\
\hline Do not know & $8(16.0)$ & $12(24.0)$ & $20(20.0)$ & & & \\
\hline \multicolumn{7}{|l|}{ History of stroke } \\
\hline Yes & $14(28.0)$ & $0(0.0)$ & $14(14.0)$ & 16.2 & 1 & $*<0.00$ \\
\hline No & $36(72.0)$ & $50(100.0)$ & $86(86.0)$ & 8 & & 1 \\
\hline
\end{tabular}


UK. LDL cholesterol was calculated using Friedewald's formula [11]. Apo A-1 and Apo B were analyzed by ELISA technique using kit manufactured by SPAN BIOTECH LIMITED (Batch Numbers; E201509198048, E201509198049), Hong Kong.

Table 3: Comparison of anthropometric measurements and biochemical parameters

\begin{tabular}{lcccc} 
Variables & Cases & Controls & $\boldsymbol{t}$-test & $\boldsymbol{P}$ value \\
Weight $(\mathrm{kg})$ & $69.92 \pm 13.54$ & $63.58 \pm 13.92$ & 2.309 & $* 0.023$ \\
Height $(\mathrm{m})$ & $1.6 \pm 0.9$ & $1.61 \pm 0.08$ & 0.646 & 0.520 \\
Waist $(\mathrm{cm})$ & $84.24 \pm 14.94$ & $78.2 \pm 22.16$ & 1.582 & 0.117 \\
Hip $(\mathrm{cm})$ & $91.32 \pm 20.77$ & $85.34 \pm 23.41$ & 1.351 & 0.80 \\
SBP $(\mathrm{mmHg})$ & $154.96 \pm 32.64$ & $117.52 \pm 16.83$ & 7.208 & $* *<0.001$ \\
DBP $(\mathrm{mmHg})$ & $90.6 \pm 19.15$ & $71.32 \pm 11.66$ & 6.080 & $* *<0.001$ \\
Body fat $(\%)$ & $33.48 \pm 6.45$ & $29.57 \pm 7.91$ & 2.710 & $* 0.008$ \\
BMI & $26.59 \pm 4.21$ & $24.01 \pm 5.55$ & 2.606 & $* 0.011$ \\
Waist/hip & $0.96 \pm 0.24$ & $0.91 \pm 0.09$ & 1.142 & 0.256 \\
FPG (mmol/1) & $5.20 \pm 1.79$ & $4.99 \pm 1.23$ & 0.91 & 0.365 \\
T-CHO (mmol/L) & $4.58 \pm 1.41$ & $3.90 \pm 0.91$ & 2.86 & $* 0.005$ \\
HDL (mmol/L) & $0.76 \pm 0.32$ & $1.27 \pm 0.38$ & -7.23 & $* *<0.001$ \\
LDL (mmol/L) & $3.32 \pm 1.41$ & $2.19 \pm 0.82$ & 4.88 & $* *<0.001$ \\
TRIG (mmol/L) & $1.11 \pm 0.68$ & $0.97 \pm 0.45$ & 1.212 & 0.228 \\
APO A1 (mg/ml) & $0.87 \pm 0.73$ & $4.56 \pm 2.40$ & -10.41 & $* *<0.001$ \\
APO B (mg/ml) & $1.55 \pm 0.97$ & $1.45 \pm 1.40$ & 0.49 & 0.628 \\
Apo B/Apo A1 & $3.12 \pm 2.37$ & $0.40 \pm 0.27$ & 8.066 & $* *<0.001$ \\
\hline
\end{tabular}

HDL: High-density lipoproteins, LDL: Low-density lipoprotein, FPG: Fasting plasma glucose
The data obtained were analyzed using SPSS version 20. Frequency distribution tables were generated from variables such as age, sex, religion, marital status, and ethnicity, while cross-tabulation and test statistics were done. The Chi-square test was used to compare proportion, while Student's $t$-test was used to compare means of continuous variables. The analysis of variance test was used to compare means of more than two variables. Pearson's correlation analysis was used to test the strength and direction of relationship between continuous variables. Level of statistical significance was set with $P \leq 0.05$.

\section{RESULTS}

As shown in Table 1, the age range for controls and subjects was between 30 and 95 years. There was no significant difference in the mean age when compared subjects with controls. $76 \%$ of subjects had ischemic stroke while $24 \%$ had hemorrhagic stroke.

Table 2 subjects which statistically significant were hypertensive $(P<0.001)$, diabetic $(P=0.012)$, and alcoholic for more than 10 years $(P=0.015)$, have family history of hypertension $(P<0.001)$, diabetes $(P=0.029)$, and history of stroke $(P<0.001)$ than the controls. More subjects, also statistically significant, were found to take antihypertensives $(P<0.001)$ and hypoglycemic agents $(P=0.012)$ than controls, but more people among controls did engage in one form of exercise $(P<0.001)$ than the subjects.

There were significantly elevated mean values of SBP (154.96 \pm $32.64)$ and DBP (117.52 \pm 16.83$)$ in subjects than the controls; SBP $(117.52 \pm 16.83)$ and DBP $(71.32 \pm 11.66)(P<0.001)$. Mean body weight $(69.92 \pm 13.54 \mathrm{~kg})$, body fat $(33.48 \pm 6.45)$, and body mass index $(\mathrm{BMI})(26.59 \pm 4.21)$ in subjects were higher than that of the

Table 4: Correlation of plasma level of FPG, T-Chol, HDL, LDL, TRIG, Apo A1, and Apo B in patients with ischemic stroke

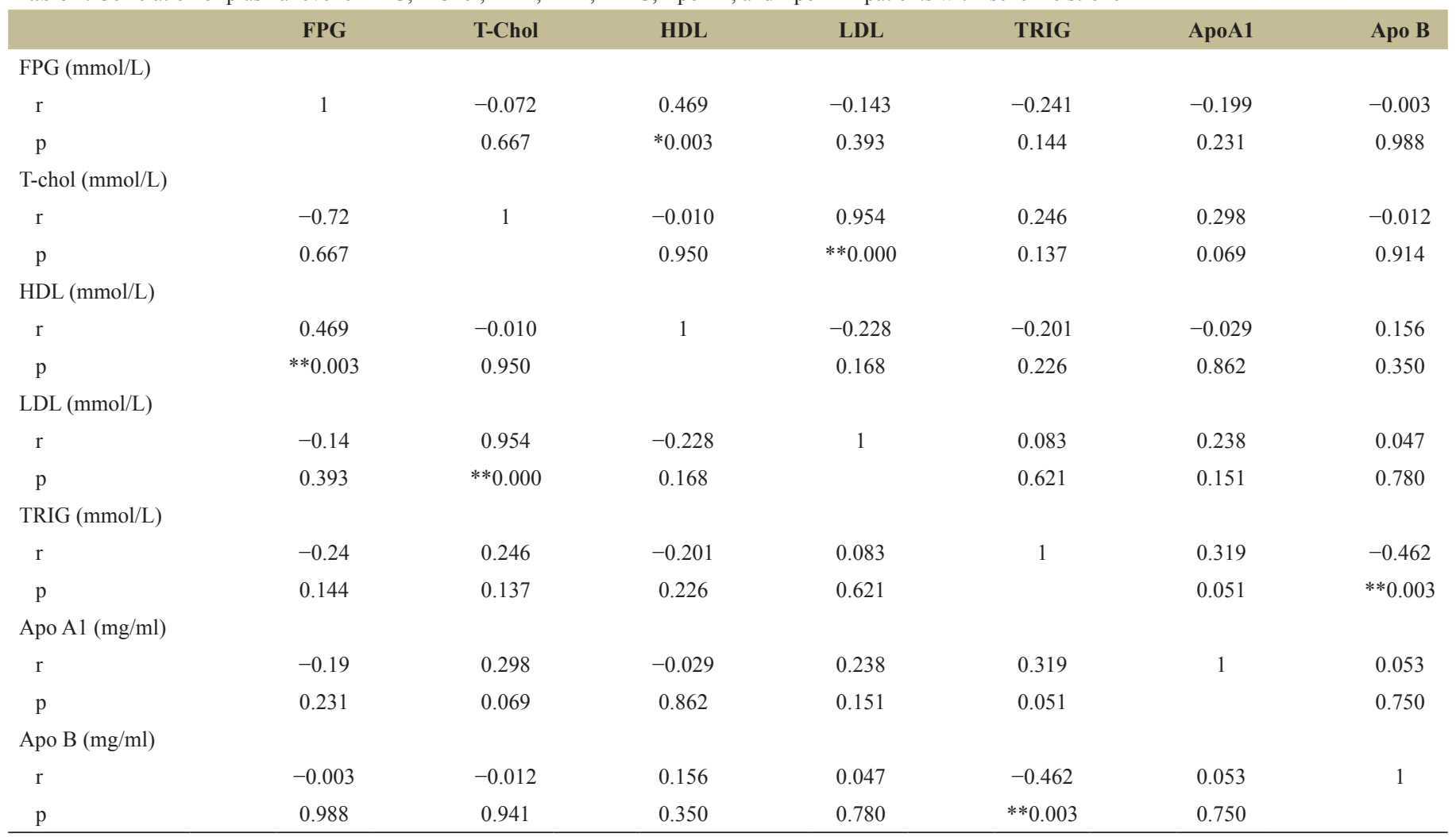

HDL: High-density lipoproteins, LDL: Low-density lipoprotein, FPG: Fasting plasma glucose 
controls (body weight $=63.58 \pm 13.92$, body fat $=29.57 \pm 7.91$, and $\mathrm{BMI}=24.01 \pm 5.55)(P<0.005)$. The waist/hip ratio $(0.96 \pm 0.24)$ in subjects was not significantly different when compared with controls $(0.91 \pm 0.09)$. Higher and lower significant levels $(P<0.001)$, respectively, were observed in the plasma total cholesterol $(4.5 \pm$ 1.41 vs. $3.90 \pm 0.91 \mathrm{mmol} / \mathrm{l})$, LDL-cholesterol (3.32 \pm 1.41 vs. $2.19 \pm$ $0.82 \mathrm{mmol} / \mathrm{l})$, HDL-cholesterol $(0.76 \pm 0.32 \mathrm{vs} .1 .27 \pm 0.38 \mathrm{mmol} / \mathrm{l})$, and APO A1 $(0.87 \pm 0.73$ vs. $4.56 \pm 2.40)$ in stroke patients than in the controls. These are presented in Table 3.

There were no significant differences between the levels of FPG, triglyceride, and APO B in subjects and controls $(P>0.05)$. Apo B/ ApoA1 ratio was significantly higher in subjects than the controls $(P<0.001)$.

In Tables 4 and 5, very strong and highly significant positive association was found between total cholesterol and LDL-cholesterol in subjects with ischemic stroke $(r=0.954, P<0.01)$ and hemorrhagic stroke $(r=0.957, P<0.01)$. There was a significant negative association between triglyceride and Apo B $(r=-0.462 ; P=0.003)$ in patients with ischemic stroke. A highly significant but weak negative correlation was observed between triglyceride and Apo B $(r=-0.462, P=0.003)$ in patients with ischemic stroke.

\section{DISCUSSION}

Hypertension was the major risk factor for stroke in about threequarters of the subjects, and the number of respondents diagnosed with hypertension was found to be significantly higher among subjects than controls $(P<0.001)$. This has been observed in many other studies also [12].
In the present study, all lipid parameters (except Apo B and triglyceride) measured in the plasma of patients with stroke were significantly higher compared to the controls. The mean value of Apo B was found to be higher in subjects than controls but was not statistically significant. This is contrary to the reports of most literature which associated the increased Apo B level in plasma with increased risk of CVD and stroke [13,14]. Apo B represents the total number of circulating atherogenic particles [15]. In this study, Apo B/Apo A1 ratio was significantly higher in subjects compared with controls. This is well documented in several studies [4,16], and Apo B/Apo A1 ratio has been shown to be a better predictor of CVD events and stroke than conventional lipid profile [17].

Regarding Apo A1, there are numerous evidences that supported the association of low plasma level of Apo A1 in stroke patients [15]. The present study also found significantly low plasma level of Apo A1 in stroke patients.

The plasma level of total cholesterol was found to be significantly higher in subjects when compared with controls. Although, the association between blood total cholesterol and risk of stroke is of public health importance. However this remains a controversial. Some studies found elevated plasma total cholesterol level in patients with stroke [17,18], which is similar to that obtained in this study. Elevated total cholesterol showed a weak positive association with strokes in some studies [17,19], while other studies found no clear association [20,21].

The present study found mean plasma level of triglyceride to be higher in stroke patients compared with controls but not statistically significant. This may be due to low level of triglyceride (paradox) among Africans $[9,22]$. Plasma level of triglyceride and risk of stroke

Table 5: Correlation of plasma level of FPG, T-Chol, HDL, LDL, TRIG, Apo A1, and Apo B in patients with hemorrhagic stroke $n=12$

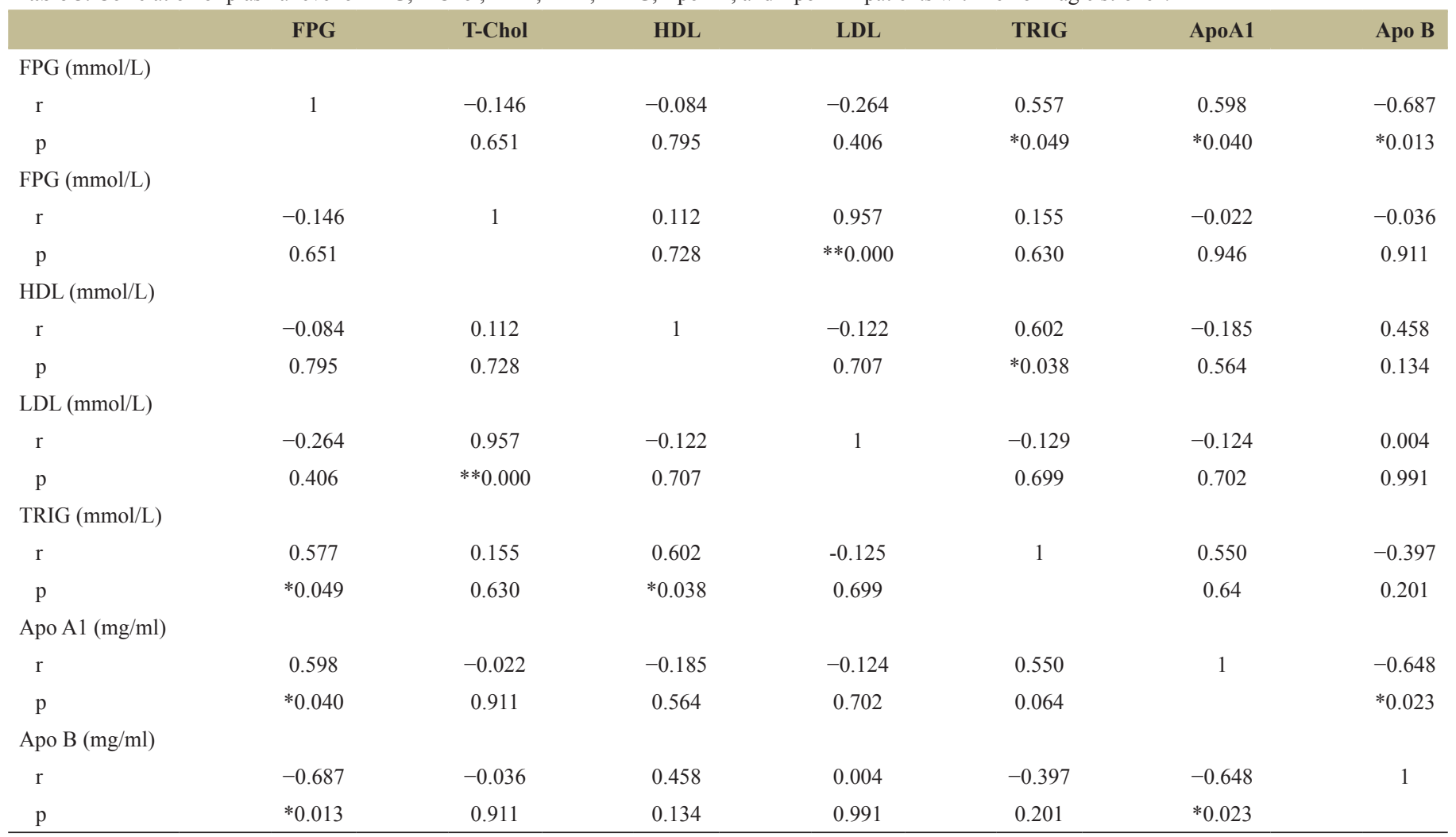

HDL: High-density lipoproteins, LDL: Low-density lipoprotein, FPG: Fasting plasma glucose 
has been reported to be a controversial issue. One study revealed that low triglyceride levels were associated with worse stroke as assessed by the National Institutes of Stroke Scale at presentation [23].

The true association between LDL-cholesterol and the risk of stroke remains unknown and results from many studies are not unanimous [24]. In this present study, plasma level of LDL-cholesterol was found to be significantly higher in patients with stroke compared with controls. This is in agreement with other studies which reported that statins significantly reduced the risk of stroke [24,25].

In this study, the HDL-cholesterol level was significantly lower in stroke patients compared with controls. This confirms the fact that low HDL-cholesterol is a risk factor for stroke. Several studies have also reported inverse relationship between stroke and plasma level of HDLcholesterol [26,27].

As presented in Tables 4 and 5, various degrees of associations were observed among the measured biochemical parameters. Very strong positive significant association was observed between total cholesterol and LDL-cholesterol. This is expected since LDL-cholesterol is the major contributor of the high level of cholesterol found in stroke patients, especially in Blacks $[9,22]$.

A significant but weak positive correlation existed between FPG and HDL-cholesterol in ischemic stroke. This is contrary to most findings where poor glycemic control and low HDL-cholesterol are risk factors for stroke and not increase in HDL-cholesterol $[28,29]$. There may be a significant association between the two, but larger sample size may be needed to determine the direction of the association.

A negative correlation and high significant association were observed between triglyceride and Apo B. Although increase in plasma level of both triglyceride and Apo B has been reported in studies contrary to this present study [30,31], this may be due to triglyceride paradox in Blacks $[9,22]$. Further studies may be needed to clarify this difference.

\section{CONCLUSION AND RECOMMENDATIONS}

It is observed that ischemic stroke is more common than hemorrhagic stroke. Stroke occurred more in the elderly postmenopausal women. Cardiovascular risk factors were significantly higher in patients with stroke compared with controls. In view of the significant positive association between ApoA1, Apo B/ApoA1 ratio, total cholesterol, HDL-cholesterol and LDL-cholesterol, apoproteins should be included in routine investigations as predictor of cerebrovascular events in this environment.

\section{REFERENCES}

1. Ogun A, Ojini F, Ogbungbo B, Kolapo K. Stroke in South West Nigeria. Stroke 2005;36:1120-2.

2. Grace M, Jabcob KJ, Kumar AR, Shameer VK. Role of dyslipidemia in stroke and comparison of lipid profile in ischemic and hemorrhagic stroke - A case control study. Int J Adv Med 2016;3:694-8.

3. Gotto AM Jr. Farmer JA. Reducing the risk for stroke in patients with myocardial infarction: A Myocardial ischemia reduction with aggressivecholesterollowering(MIRACL) substudy.Circulation2002; 106:1595-8.

4. Malati $T$, Mahesh MR. Reference intervals for serum total cholesterol, HDL-cholesterol, LDL-cholesterol, triglycerides, lp (a), apolipoprotein A-I, A-II, B, C-II, C-III, and E in healthy south indians from andhra pradesh. Indian J Clin Biochem 2009;24:343-55.

5. Filou S, Lhomme M, Karavia EA, Kalogeropoulou C,
Theodoropoulos V, Zvintzou E, et al. Distinct roles of apolipoproteins $\mathrm{A} 1$ and $\mathrm{E}$ in the modulation of high-density lipoprotein composition and function. Biochemistry 2016;55:3752-62.

6. Song X, Fischer P, Chen X, Burton C, Wang J. An apoA-I mimetic peptide facilitates off-loading cholesterol from HDL to liver cells through scavenger receptor BI. Int J Biol Sci 2009;5:637-46.

7. Benoit L, Sitaal M, Paul J. Apolipoprotein A-I and B levels and the risk of ischemic heart disease during a five-year follow-up of men in the que'bec cardiovascular study. Circulation 1996;94:273-8.

8. Tognon G, Berg C, Mehlig K, Thelle D, Strandhagen E, Gustavsson J, et al. Comparison of apolipoprotein (apoB/apoA-I) and lipoprotein (total cholesterol/HDL) ratio determinants. Focus on obesity, diet and alcohol intake. PLoS One 2012;7:e40878.

9. Yu SS, Castillo DC, Courville AB, Sumner AE. The triglyceride paradox in people of african descent. Metab Syndr Relat Disord 2012; 10:77-82.

10. Gould A, Asare H, Akpalu A, Cullen L, Easton S, Jarrett D, et al. Development of stroke care in ghana. Int J Stroke 2011;6:150-1.

11. Krishnaveni P, Gowda VM. Assessing the validity of friedewald's formula and anandraja's formula for serum LDL-cholesterol calculation. J Clin Diagn Res 2015;9:BC01-4.

12. Kim AS, Johnston SC. The current state and future of stroke temporal and geographic trends in the global stroke epidemic. Stroke 2013;44:2013-6.

13. Park JH, Hong KS, Lee EJ, Lee J, Kim DE. High levels of apolipoprotein $\mathrm{B} / \mathrm{AI}$ ratio are associated with intracranial atherosclerotic stenosis. Stroke 2011;42:3040-6.

14. Walldius G. In: Frank S, Kostner G, editors. The apoB_apoA-I Ratio is a Strong Predictor of Cardiovascular Risk. Sweden: Biochemistry, Genetics and Molecular Biology; 2012. p. 773-6.

15. Dominiczak MH, Caslake MJ. Apolipoproteins: Metabolic role and clinical biochemistry applications. Ann Clin Biochem 2011; 48:498-515.

16. Benn M. Apolipoprotein B levels, APOB alleles, and risk of ischemic cardiovascular disease in the general population, a review. Atherosclerosis 2009;206:17-30.

17. Wannamethee SG, Shaper AG, Ebrahim S. HDL-cholesterol, total cholesterol,andtheriskofstrokeinmiddle-agedbritishmen. Stroke2000; 31:1882-8.

18. Bhatia M, Howard SC, Clark TG, Neale R, Qizilbash N, Murphy MF, et al. Apolipoproteins as predictors of ischaemic stroke in patients with a previous transient ischaemic attack. Cerebrovasc Dis 2006;21:323-8.

19. Park J, Kwon H. Associaotion between metabolic syndrome and previous ishaemic stroke. Clin Neurol Neurosurg 2008;110:215-21.

20. Bowman TS, Sesso HD, Ma J, Kurth T, Kase CS, Stampfer MJ, et al. Cholesterol and the risk of ischemic stroke. Stroke 2003;34:2930-4.

21. Shahar E, Chambless LE, Rosamond WD, Boland LL, Ballantyne CM, McGovern PG, et al. Plasma lipid profile and incident ischemic stroke: The atherosclerosis risk in communities (ARIC) study. Stroke 2003;34:623-31.

22. Sumner AE. Ethnic differences in triglyceride levels and high-density lipoprotein lead to under diagnosis of the metabolic syndrome in black children and adults. J Pediatr 2009;155:S7.e7-11.

23. Jain M, Jain A, Yerragondu N, Brown RD, Rabinstein A, Jahromi BS, et al. The triglyceride paradox in stroke survivors: A Prospective study. Neurosci J 2013;2013:870608.

24. Imamura T, Doi Y, Arima H, Yonemoto K, Hata J, Kubo M, et al. LDL cholesterol and the development of stroke subtypes and coronary heart disease in a general japanese population: The Hisayama study. Stroke 2009;40:382-8.

25. Williams PT, Zhao XQ, Marcovina SM, Brown BG, Krauss RM. Levels of cholesterol in small LDL particles predict atherosclerosis progression and incident CHD in the HDL-atherosclerosis treatment 
study (HATS). PLoS One 2013;8:e56782.

26. Luo Y, Li J, Zhang J, Xu Y. Low HDL cholesterol is correlated to the acute ischemic stroke with diabetes mellitus. Lipids Health Dis 2014; 13:171.

27. Reina SA, Llabre MM, Allison MA, Wilkins JT, Mendez AJ, Arnan MK, et al. HDL cholesterol and stroke risk: The multi-ethnic study of atherosclerosis. Atherosclerosis 2015;243:314-9.

28. Chien KL, Sung FC, Hsu HC, Su TC, Lin RS, Lee YH. Apolipoprotein A-I and B and stroke events in a community-based cohort in Taiwan. Stroke 2002;33:39-44.

29. Hayashi T, Kawashima S, Itoh H, Yamada N, Sone H, Watanabe H, et al. Low HDL cholesterol is associated with the risk of stroke in elderly diabetic individuals: Changes in the risk for atherosclerotic diseases at various ages. Diabetes Care 2009;32:1221-3.
30. Guan Y, Yu C, Shi M, Ni J, Wu Y, Gu H, et al. The association between elevated fasting plasma glucose levels and carotid intimamedia thickness in non-diabetic adults: A population-based crosssectional study. Oncotarget 2017;8:111053-63.

31. Rhoads GG, Feinleib M. Serum triglyceride and risk of coronary heart disease, stroke, and total mortality in Japanese-American men. Arteriosclerosis 1983;3:316-22.

How to cite this article:

Akande JO, Oparinde DP, Salawu AA, Atiba AS, Oke EO, Akande RO,

Ogunro PS. Plasma levels of total cholesterol, high-density lipoprotein-

cholesterol, low-density lipoprotein-cholesterol, triglyceride, Apo A-1, and

Apo B in patients with Stroke in Ogbomoso, Southwestern Nigeria J App

Biol Biotech. 2019;7(03):29-35. DOI: 10.7324/JABB.2019.70306 